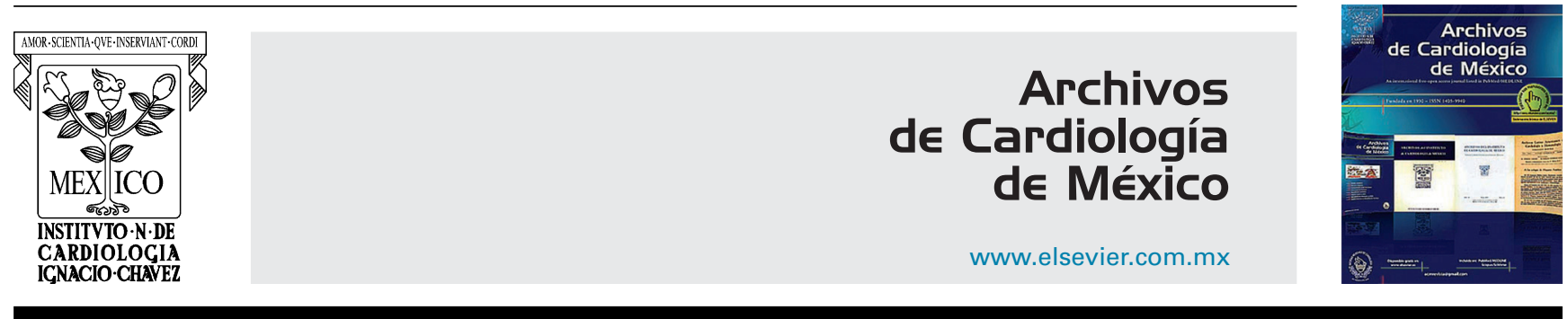

IMAGEN EN CARDIOLOGÍA

\title{
Marcapasos transcatéter sin cables, en paciente con prótesis mitral mecánica
}

\section{Trascatheter leadless pacemaker in a patient with mitral mechanical prosthesis}

\author{
Marta Pachón, Finn Akerström, Alberto Puchol, Luis Rodríguez-Padial y Miguel A. Arias*
}

Unidad de Arritmias y Electrofisiología Cardiaca, Servicio de Cardiología, Hospital Virgen de la Salud, Toledo, España

Recibido el 3 de noviembre de 2015; aceptado el 20 de mayo de 2016

Una mujer de 75 años con estenosis mitral severa por cardiopatía reumática, fue sometida a cirugía cardiaca para recambio valvular, implantándose una prótesis mitral mecánica. La paciente estaba en fibrilación auricular crónica, previo a la cirugía, y 5 días tras la misma, y sin incidencias en el postoperatorio, la paciente presentaba una respuesta ventricular errática con periodos de bradicardia extrema sintomática, estableciéndose la indicación de marcapasos definitivo. Estaba bajo tratamiento con acenocumarol y presentaba una insuficiencia tricúspide grado II, con una presión sistólica pulmonar de $50 \mathrm{mmHg}$. Para tratar de evitar los problemas relacionados con la bolsa del marcapasos y con los cables, se decidió implante de un marcapasos sin cables transcatéter Micra ${ }^{\circledR 1,2}$ (Medtronic, Minneapolis, EE.UU.) (fig. 1A) que se realizó por vía venosa femoral derecha, sin interrupción de la anticoagulación y con un INR de 2,2. Se implantó el sistema a nivel medioseptal ventricular derecho sin incidencias (fig. 1B), obteniendo un umbral de $0,25 \mathrm{~V}$ a $0,24 \mathrm{~ms}$, una onda $\mathrm{R}$ de $12,8 \mathrm{mV}$ y una impedancia de estimulación de $800 \Omega$. Se realizó hemostasia mediante sutura subcutánea en 8 , sin complicaciones. Fue dada de alta al día siguiente, tras corroborar la normoposición del marcapasos en una radiografía de tórax (figs. 1C y D) y la estabilidad de los parámetros eléctricos del marcapasos. Tras un mes del implante la paciente se encuentra asintomática, con un $30 \%$ de estimulación por el marcapasos (fig. 1E). El marcapasos transcatéter Micra ${ }^{\circledR}$ consiste en una cápsula de $8 \mathrm{~cm}^{3}$ de volumen, con unas dimensiones de $25,9 \times 6,7 \mathrm{~mm}$, y permite la estimulación cardiaca bipolar en modo VVI en ventrículo derecho. El marcapasos se implanta mediante un catéter deflectable, que a su vez va por dentro de un introductor de 27 french de diámetro externo, introducido a través de la vena femoral.

\footnotetext{
* Autor para correspondencia. Unidad de Arritmias y Electrofisiología Cardiaca, Avenida de Barber 30, 45004 Toledo, España.

Correo electrónico: maapalomares@secardiologia.es (M.A. Arias).
} 

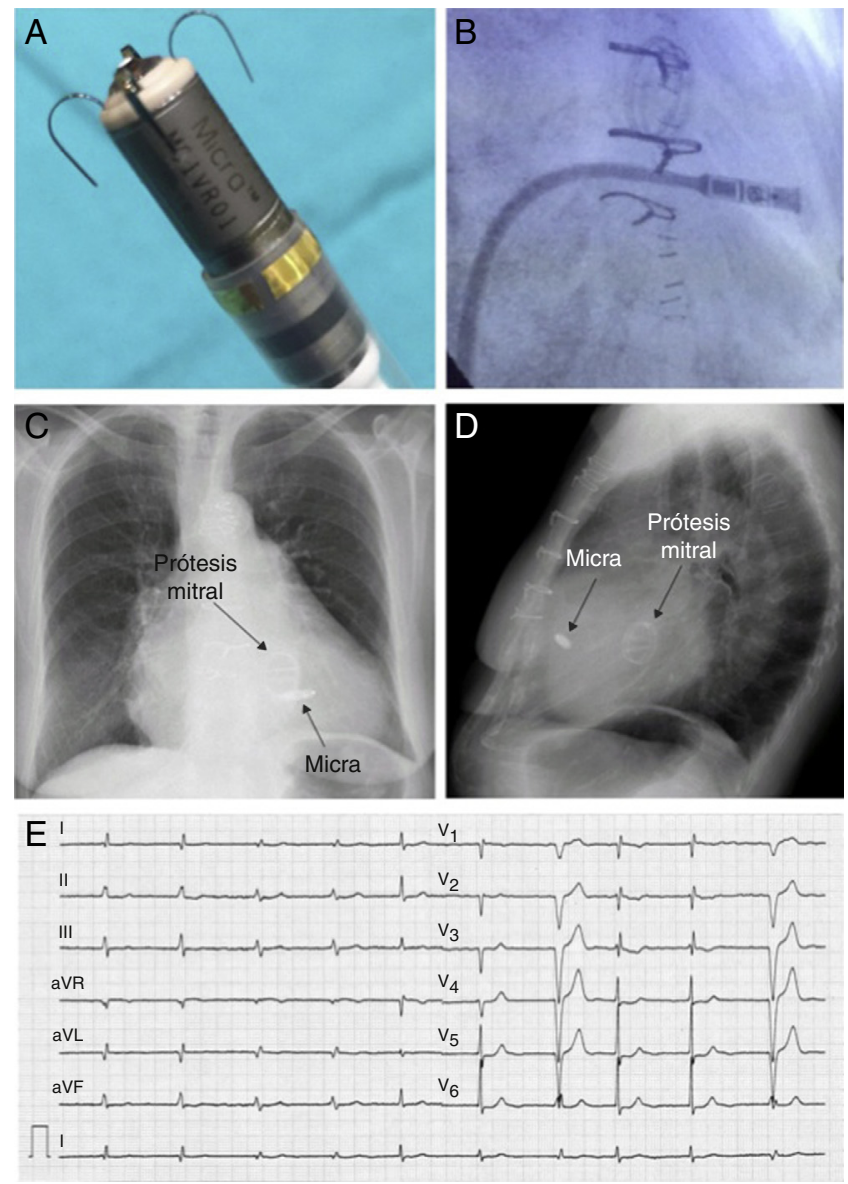

Figura 1 A) Detalle del marcapasos, parcialmente expuesto en el extremo distal del catéter de liberación; B) Imagen de fluoroscopia en oblicua anterior derecha, previa a la liberación del marcapasos en endocardio; C) Radiografía posteroanterior de tórax, al mes del implante; D) Radiografía lateral de tórax, al mes del implante; E) Electrocardiograma de 12 derivaciones, tras el implante de marcapasos, donde se observan tanto complejos nativos de la paciente como complejos estimulados.

\section{Responsabilidades éticas}

Protección de personas y animales. Los autores declaran que para esta investigación no se han realizado experimentos en seres humanos ni en animales.

Confidencialidad de los datos. Los autores declaran que han seguido los protocolos de su centro de trabajo sobre la publicación de datos de pacientes.

Derecho a la privacidad y consentimiento informado. Los autores han obtenido el consentimiento informado de los pacientes y/o sujetos referidos en el artículo.

\section{Financiación}

No se recibió patrocinio de ningún tipo para llevar a cabo este estudio.

\section{Conflicto de intereses}

Los autores declaran no tener conflicto de intereses.

\section{Bibliografía}

1. Ritter P, Duray GZ, Steinwender C, et al. Early performance of a miniaturized leadless cardiac pacemaker: The Micra Transcatheter Pacing Study. Eur Heart J. 2015;36:2510-9.

2. Pachón M, Puchol A, Arias MA. Marcapasos sin cables tras hematoma complicado. Rev Esp Cardiol. 2016;69:346-9. 